\title{
Article \\ Genetic Engineering of Lesquerella with Increased Ricinoleic Acid Content in Seed Oil
}

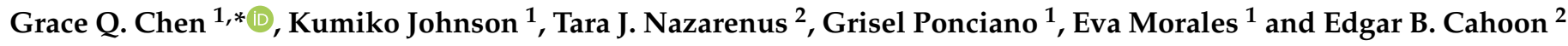 \\ 1 Western Regional Research Center, Agricultural Research Service, U.S. Department of Agriculture, \\ 800 Buchanan St., Albany, CA 94710, USA; kumiko.johnson@usda.gov (K.J.); \\ Grisel.ponciano@usda.gov (G.P.); evadesalta@gmail.com (E.M.) \\ 2 Department of Biochemistry and Center for Plant Science Innovation, University of Nebraska-Lincoln, \\ Lincoln, NE 68588, USA; tnazarenus2@unl.edu (T.J.N.); ecahoon2@unl.edu (E.B.C.) \\ * Correspondence: grace.chen@usda.gov
}

Citation: Chen, G.Q.; Johnson, K.; Nazarenus, T.J.; Ponciano, G.; Morales, E.; Cahoon, E.B. Genetic Engineering of Lesquerella with Increased Ricinoleic Acid Content in Seed Oil. Plants 2021, 10, 1093. https://doi.org/10.3390/plants 10061093

Academic Editor: Rebecca Grumet

Received: 29 April 2021

Accepted: 27 May 2021

Published: 29 May 2021

Publisher's Note: MDPI stays neutral with regard to jurisdictional claims in published maps and institutional affiliations.

Copyright: (C) 2021 by the authors. Licensee MDPI, Basel, Switzerland. This article is an open access article distributed under the terms and conditions of the Creative Commons Attribution (CC BY) license (https:/ / creativecommons.org/licenses/by/ $4.0 /)$.
Abstract: Seeds of castor (Ricinus communis) are enriched in oil with high levels of the industrially valuable fatty acid ricinoleic acid $(18: 1 \mathrm{OH})$, but production of this plant is limited because of the cooccurrence of the ricin toxin in its seeds. Lesquerella (Physaria fendleri) is being developed as an alternative industrial oilseed because its seeds accumulate lesquerolic acid (20:1OH), an elongated form of $18: 1 \mathrm{OH}$ in seed oil which lacks toxins. Synthesis of $20: 1 \mathrm{OH}$ is through elongation of $18: 1 \mathrm{OH}$ by a lesquerella elongase, PfKCS18. Oleic acid (18:1) is the substrate for 18:1OH synthesis, but it is also used by fatty acid desaturase 2 (FAD2) and FAD3 to sequentially produce linoleic and linolenic acids. To develop lesquerella that produces 18:1OH-rich seed oils such as castor, RNA interference sequences targeting $K C S 18, F A D 2$ and FAD3 were introduced to lesquerella to suppress the elongation and desaturation steps. Seeds from transgenic lines had increased $18: 1 \mathrm{OH}$ to $1.1-26.6 \%$ compared with that of $0.4-0.6 \%$ in wild-type (WT) seeds. Multiple lines had reduced 18:1OH levels in the $\mathrm{T}_{2}$ generation, including a top line with $18: 1 \mathrm{OH}$ reduced from $26.7 \%$ to $19 \%$. Transgenic lines also accumulated more $18: 1$ than that of WT, indicating that $18: 1$ is not efficiently used for $18: 1 \mathrm{OH}$ synthesis and accumulation. Factors limiting 18:1OH accumulation and new targets for further increasing 18:1OH production are discussed. Our results provide insights into complex mechanisms of oil biosynthesis in lesquerella and show the biotechnological potential to tailor lesquerella seeds to produce castor-like industrial oil functionality.

Keywords: hydroxy fatty acid; ricinoleic acid; lesquerolic acid; triacylglycerol; Physaria fendleri; lesquerella; seed oil; RNA interference; genetic transformation

\section{Introduction}

The conventional source of hydroxy fatty acid (HFA) is castor (Ricinus communis), which contains $90 \%$ ricinoleic acid $(18: 10 H)$ in its seed oil. The fatty acid and its derivatives are used as feedstocks for numerous industrial products, such as lubricants, plastics and surfactants [1,2]. The production of castor oil is hampered by the presence of the toxin ricin [3,4] and hyper-allergenic $2 S$ albumins [5-7] in its seeds. Lesquerella (Physaria fendleri, Brassicaceae) seed oil contains a major HFA, lesquerolic acid (20:1OH) at 55-60\% [8-11], and seeds of this plant lack any known toxins. As such, efforts have been made through plant breeding to develop lesquerella as a new oilseed crop that is a safe source of HFA [12,13]. With the success of lesquerella biotechnology $[14,15]$ and the deep knowledge of genes for fatty acid and seed oil biosynthesis [16-18], lesquerella oil can be improved through metabolic engineering [15].

Seed oil (triacylglycerol, TAG) starts from de novo fatty acid (FA) biosynthesis in plastid and TAG assembly in endoplasmic reticulum (ER) [16]. Simplified pathways and genes in lesquerella TAG synthesis are shown in Figure 1. 


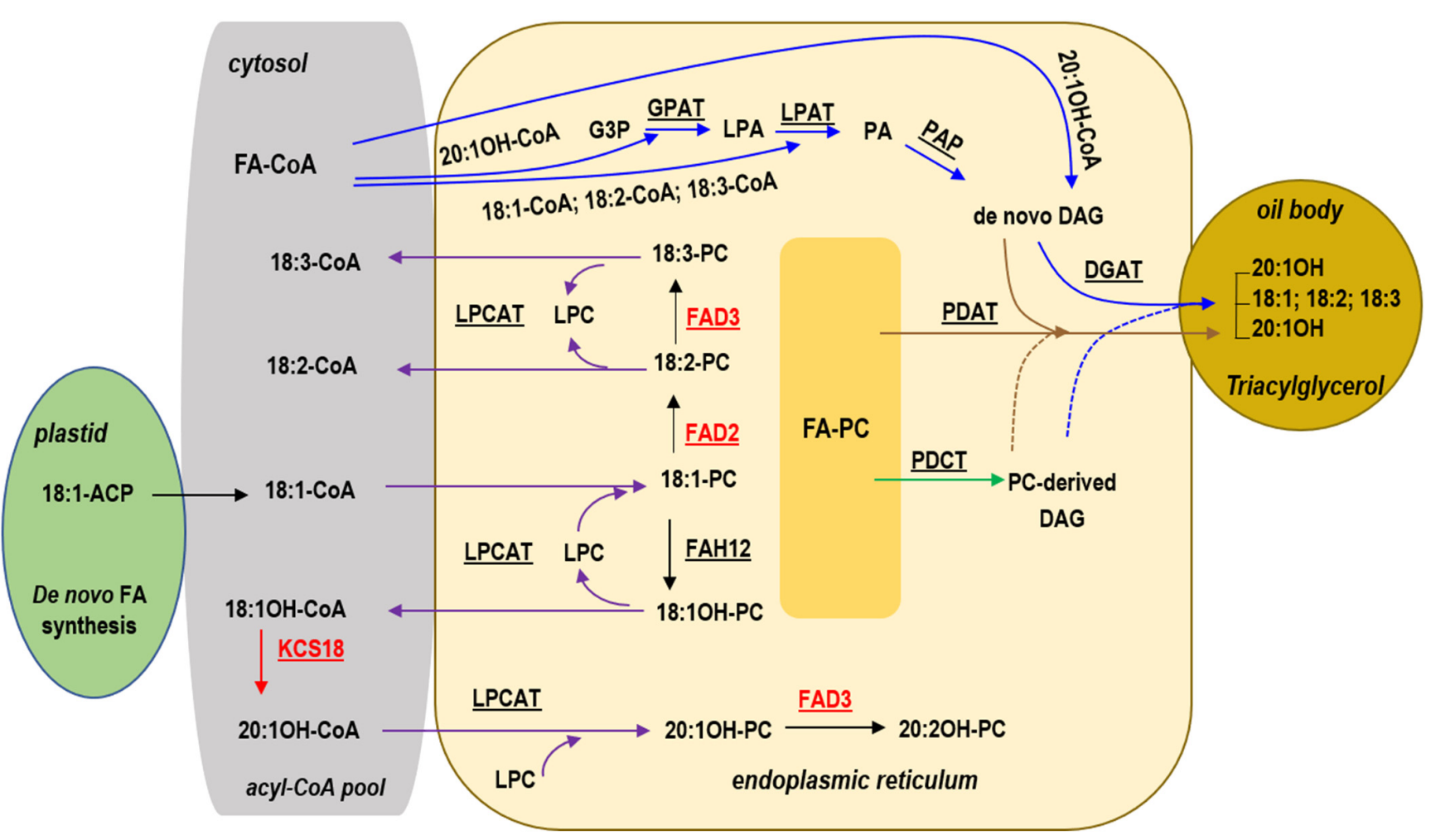

Figure 1. Simplified pathways for fatty acid and triacylglycerol synthesis in lesquerella seeds. Blue arrows indicate reactions involved in the Kennedy pathway. Purple arrows indicate reactions involved in acyl editing by LPCAT. Brown arrows indicate PDAT-mediated pathways. Green arrow indicates reactions involved in PC-derived DAG synthesis. Dotted lines indicate PC-derived DAG utilized by DGAT and PDAT. The red arrow indicates the elongation step by KCS18. Enzymes catalyzing these reactions are underlined. Red fonts are the targeted enzymes in this study. Fatty acid numerical symbols: 18:1, oleic acid; $18: 1 \mathrm{OH}$, ricinoleic acid; 20:1OH, lesquerolic acid; 20:2OH, auricolic acid; 18:2, linoleic acid; 18:3, linolenic acid. Abbreviations: CoA, co-enzyme A; PC, phosphatidylcholine; LPCAT, lysophosphatidylcholine acyltransferase; LPC, lysophosphatidylcholine; FAH12, $\triangle 12$ oleic acid hydroxylase; KCS18, 3-ketoacyl-CoA synthase 18; G3P, glycerol-3-phosphate; LPA, lysophosphatidic acid; PA, phosphatidic acid; DAG, diacylglycerol; GPAT, glycerol 3-phosphate acyltransferase; LPAT, lysophosphatidic acid acyltransferase; PAP, phosphatidic acid phosphatase; DGAT, diacylglycerol acyltransferase; PDAT, phospholipid:DAG acyltransferase; PDCT, PC:DAG cholinephosphotransferase; TAG, triacylglycerol.

During lesquerella seed development, oleic acid (18:1) is synthesized in plastid, exported and activated to 18:1-Coenzyme A (CoA) in the cytosol. The 18:1-CoA can be acylated directly into membrane lipid phosphatidylcholine (PC) in the ER by the forwarding reaction of lyso-PC acyltransferase (LPCAT) [19-21] resulting in 18:1-PC (Figure 1). The 18:1-PC is the substrate of oleate 12-hydroxylase (FAH12) [22-25] which hydroxylates 18:1-PC to form 18:1OH-PC (Figure 1). Lesquerella PfFAH12 is bi-functional FAD2-related oleate $\Delta 12$-hydroxylase:desaturase that converts $18: 1-\mathrm{PC}$ to both $18: 1 \mathrm{OH}-\mathrm{PC}$ and linoleic acid (18:2)-PC [25]. Through the reverse reaction of LPCAT (Figure 1), or phospholipase A (PLA2)-type activity [26], the 18:1OH can be removed from PC, following its synthesis on this lipid, and transferred back to cytosol to be activated as 18:1OH-CoA. A lesquerella seed fatty acid condensing enzyme (PfKCS18) (also known as KCS3 or FAE1, all designations used in this article) elongates 18:1OH-CoA to 20:1OH-CoA [27] (Figure 1). Rapid acylation and de-acylation by LPCAT (or by PLA2), and in conjunction with efficient elongation by PfKCS18 leads to enrichment of 20:1OH-CoA in cytosol. PC is also the substrate for FA desaturase 2 (FAD2) [28] and FA desaturase 3 (FAD3) [29] that sequentially converts 18:1 to $18: 2$ and 18:2 to linolenic acids (18:3), respectively (Figure 1). In addition to 20:1OH, 18:1OH, 18:1, 18:2 and 18:3, lesquerella oil contains auricolic acid (20:2OH), also formed by FAD3 [30,31]. Lesquerella PfFAD3-1 is a key enzyme producing 18:3 and 20:2OH [32]. FA- 
CoA in cytosol or FA-PC in ER are assembled to TAG through multiple mechanisms $[16,19]$ (Li 2013; Bates 2016). Kennedy pathway [33] is the major route for FA esterification into TAG, which consists of three sequential acylations of FA-CoAs to a glycerol-3-phosphate (G3P) backbone. The sn-1 position of G3P is acylated by glycerol-3-phosphate acyltransferase (GPAT) to produce lysophosphatidic acid (LPA). The $s n-2$ position of LPA is acylated by LPA acyltransferase (LPAT) to generate phosphatidic acid (PA). PA is then converted to 1,2-sn-diacylglycerol (DAG, or de novo DAG) by PA phosphatase (PAP). Finally, the sn-3 position of DAG is acylated by 1,2-sn-diacylglycerol acyltransferase (DGAT) to produce TAG. Lesquerella TAGs contain $\sim 60 \% 20: 1 \mathrm{OH}$, and almost all of 20:1OH are acylated to the $s n-1$ and $s n-3$ positions, and the $s n-2$ positions of lesquerella TAGs are exclusively occupied by unsaturated FAs, i.e., 18:1, 18:2 and 18:3 [34-37]. The reason for lack of HFA at the $s n-2$ position of TAG has been suggested, in part, by the selectivity of lesquerella LPAT (PfLPAT) for unsaturated FA [15], which is a common feature for most plant microsomal LPAT [38]. PC can be converted to DAG (PC-derived DAG) through the removal of the head group from the PC by PC:DAG cholinephosphotransferase (PDCT) [39-41] (Figure 1); therefore, acyl-CoAs on the PC are directed to DAG for TAG synthesis. PC-derived DAG can be produced by the reverse action of CDP-choline: DAG cholinephosphotransferase (CPT) [42], a lipase-based mechanism using phospholipase C (PLC), or phospholipase D plus PAP $[19,43]$. Because FAs in sn-2-PC can be modified, (e.g., desaturation and hydroxylation), the conversion of PC into DAG also provides a means to increase the amount of modified FAs (mFAs) such as 18:2, 18:3 and 18:1OH, in sn-2-TAG. Moreover, FA on the $s n-2$ PC can be transferred to the $s n-3$ position of DAG by phospholipid:DAG acyltransferase (PDAT) [44-46] (Figure 1).

Castor genes are introduced into non-HFA-oilseed arabidopsis (Arabidopsis thaliana) or camelina (Camelina Sativa) to study the HFA biosynthesis mechanism [47]. Castor RcFAH12 was first isolated and demonstrated to be responsible for HFAs synthesis in transgenic seeds up to 17\% [24,48,49]. Additional genes, castor RcDGAT2 [50], RcPDAT1-2 (or RcPDAT1-A) [45,46], and RcPDCT [41], RcPLCL1 [43], RcLPAT2 [51,52], RcLPAT3B and RcLPATB [52], and RcGPAT9 together with RcLPAT2 and RcPDAT1A [53], are demonstrated to increase the HFAs content of transgenic arabidopsis or camelina from 17 to $28 \%$.

One of our research goals is to generate a castor-oil producing lesquerella that is safe, cost-competitive, and widely accepted as an industrial feedstock. We have previously attempted to generate a castor oil-producing lesquerella through over-expressing of a castor RcLPAT2 involved in TAG assembly. In that study we demonstrated that seed oils of transgenic lesquerella showed increase in $18: 1 \mathrm{OH}$ from $1 \%$ to $4 \%$, and castor oil-like TAGs from $5 \%$ to $14 \%$ [15]. In this study, we aimed to further enhance the $18: 1 \mathrm{OH}$ level by downregulating the expression of lesquerella PfFAD2, PfFAD3, and PfKCS18 genes using RNA interference (RNAi) technology [54,55]. A RNAi silencing approach was used to suppress an endogenous target gene expression through transgenic expression of a double-stranded RNA (dsRNA) that shares sequence homology with the target and leads to cleavage of the targeted transcripts, [54,55]. We hypothesize that suppressing FAD2 and FAD3 reduces polyunsaturated FAs (PUFAs) levels, including 18:2 and 18:3, and subsequently increases 18:1, the substrate of PfFAH12 (Figure 1). Suppressing KCS18 reduces 20:1OH and subsequently increases 18:1OH for TAG assembly. PfFAD2, PfFAD3, and PfKCS18 share high sequence homology with camelina CsFAD2, CsFAD3, and arabidopsis AtKCS18, showing 93.6\%, 95.6\%, and 82.3\%, respectively [18]. RNAi constructs, CsFAD2 RNAi, CSFAD3 RNAi and AtFEA1 RNAi, are effective in silencing corresponding gene expression in camelina [56-58]. We therefore generated transgenic lesquerella expressing CsFAD2 RNAi, CsFAD3 RNAi and AtFEA1 RNAi. We have demonstrated here that high levels of 18:1OH can be achieved by blocking the desaturation and elongation steps. Our results not only provide tools for engineering castor oil-producing lesquerella, but also enhance our understanding of the mechanisms of HFA synthesis. 


\section{Results}

2.1. Changes of FA Composition in Transgenic Lesquerella Expressing Two dsRNAs, AtFAD3 $R N A i+$ CSFAE1 RNAi

We produced 16 independent lines expressing AtFAD3 RNAi + CsFAE1 RNAi (2dsRNA) under the control of seed-specific glycinin promoters. Mendelian segregation analysis on Basta resistance of $\mathrm{T}_{1}$ seeds revealed that five lines had one transgenic locus, 10 lines had two loci, and one had more than two loci (Table S1). Variable FA compositions were observed among these 16 lines. To aid examination, line 1 to line 16 were assigned to these transgenics based on descending order in 18:1OH content in their seed oils (Table 1). Moderate positive correlation $(r=0.45, p=0.08)$ was observed between $18: 1 \mathrm{OH}$ content and transgenic copy number. In all seeds, five minor fatty acids, palmitic (16:0), palmitoleic (16:1), stearic (18:0), arachidic (20:0), and eicosenoic (20:1) acids, had very low levels and small changes from $1.6-2.3 \%, 0.3-0.8 \%, 0.9-1.8 \%, 0.1-0.3 \%, 0.4-0.8 \%$, respectively, (Table S2). When these minor FAs were combined, there were no significant differences between each transgenic line and wild-type (WT) (Table 1). Consistent with our hypothesis, we observed significant increases in 18:10H content among 13 lines ranging from 1.2\% (line 13 ) to $26.6 \%$ (line 1 ) compared with $0.6 \%$ of WT (Table 1 ) and decreases in $20: 1 \mathrm{OH}$ among lines 1-10 ranging from $19 \%$ (line 1 ) to $46.9 \%$ (line10) compared with $51.2 \%$ of WT (Table 1). Except for line 13, 18:3 was significantly reduced in all lines ranging from to $1.5 \%$ (line 14 ) to $9.6 \%$ (line 10) compared with $13.3 \%$ of WT. All transgenic lines increased in $18: 2$, ranging from $9.5 \%$ (line 13 ) to $20 \%$ (line 14) compared with $7.6 \%$ of WT (Table 1 ). Notably, 18:1 content was increased in line 1-7 and line 10, ranging from $19 \%$ (line 10) to $32.1 \%$ (line 2 ) compared with $17 \%$ of WT (Table 1 ). In all transgenic lines, 20:2OH content was reduced significantly ranging from $0-2.2 \%$ compared with $4.3 \%$ of WT (Table 1 ). Total HFA content dropped from 56\% (WT) to 42.9-53.8\% among lines 1-10 and increased slightly to $57.7-57.8 \%$ in line 15 and line 16 (Table 1 ).

Table 1. Fatty acid composition (mole \%) in T1 seeds expressing AtFAD3 RNAi + CsFAE1 RNAi.

\begin{tabular}{|c|c|c|c|c|c|c|c|c|}
\hline Line & $\begin{array}{l}\text { Total Minor } \\
\text { Fatty Acid }^{\text {a }}\end{array}$ & $18: 1$ & 18:2 & $18: 3$ & 18:1OH & $20: 10 H$ & $20: 2 \mathrm{OH}$ & $\begin{array}{c}\text { Total } \\
\text { Hydroxy } \\
\text { Fatty Acid }\end{array}$ \\
\hline wild-type & $4.7 \pm 0.4$ & $17.0 \pm 0.4$ & $7.6 \pm 0.4$ & $13.3 \pm 0.6$ & $0.6 \pm 0.2$ & $51.2 \pm 1.0$ & $4.3 \pm 0.6$ & $56.0 \pm 0.5$ \\
\hline line 1 & $4.3 \pm 0.2$ & $30.5 \pm 2.8^{* * *}$ & $16.2 \pm 1.7^{* * *}$ & $2.2 \pm 0.7^{* * *}$ & $26.6 \pm 0.2^{* * *}$ & $19.0 \pm 2.0^{* * *}$ & $0.2 \pm 0.2^{* * *}$ & $45.8 \pm 1.9^{* * *}$ \\
\hline line 2 & $5.1 \pm 0.2$ & $32.1 \pm 1.3^{* *}$ & $17.0 \pm 0.5^{* * *}$ & $1.7 \pm 0.5^{* * *}$ & $16.8 \pm 0.5^{* * *}$ & $26.1 \pm 1.0^{* * *}$ & $0.0 \pm 0.0^{* * *}$ & $42.9 \pm 0.5^{* * *}$ \\
\hline line 3 & $5.0 \pm 0.2$ & $25.5 \pm 1.9^{* *}$ & $17.6 \pm 1.2^{* * *}$ & $2.6 \pm 1.4^{* * *}$ & $16.6 \pm 1.0^{* * *}$ & $31.4 \pm 2.1^{* * *}$ & $0.5 \pm 0.4^{* * *}$ & $48.4 \pm 1.5^{* * *}$ \\
\hline line 4 & $4.7 \pm 0.4$ & $22.7 \pm 2.7 *$ & $16.8 \pm 0.6^{* * *}$ & $3.3 \pm 0.8^{* * *}$ & $11.7 \pm 2.7^{* *}$ & $39.3 \pm 5.0^{* *}$ & $0.4 \pm 0.2^{* * *}$ & $51.4 \pm 2.6^{*}$ \\
\hline line 5 & $4.7 \pm 0.2$ & $23.4 \pm 2.0^{* *}$ & $18.7 \pm 0.2^{* * *}$ & $1.8 \pm 0.6^{* * *}$ & $10.2 \pm 0.4^{* * *}$ & $40.2 \pm 1.4^{* * *}$ & $0.1 \pm 0.1^{* * *}$ & $50.5 \pm 1.5^{* * *}$ \\
\hline line 6 & $4.4 \pm 0.1$ & $20.5 \pm 1.8^{*}$ & $14.4 \pm 1.0^{* * *}$ & $6.2 \pm 0.5^{* * *}$ & $8.5 \pm 0.4^{* * *}$ & $43.7 \pm 1.4^{* *}$ & $1.2 \pm 0.1^{* * *}$ & $53.4 \pm 1.5 *$ \\
\hline line 7 & $4.1 \pm 0.1$ & $20.5 \pm 0.9^{* *}$ & $16.7 \pm 2.0^{* * *}$ & $4.9 \pm 1.7^{* * *}$ & $8.0 \pm 1.3^{* * *}$ & $45.5 \pm 2.0^{* *}$ & $0.3 \pm 0.2^{* * *}$ & $53.8 \pm 1.2 *$ \\
\hline line 8 & $4.5 \pm 0.0$ & $17.6 \pm 0.5$ & $16.1 \pm 0.5^{* * *}$ & $7.6 \pm 0.4^{* * *}$ & $7.5 \pm 0.5^{* * *}$ & $45.0 \pm 0.5^{* * *}$ & $1.3 \pm 0.2^{* * *}$ & $53.8 \pm 0.2 * *$ \\
\hline line 9 & $4.4 \pm 0.1$ & $17.9 \pm 0.5$ & $17.2 \pm 0.7^{* * *}$ & $4.3 \pm 0.7^{* * *}$ & $4.9 \pm 0.4^{* * *}$ & $49.3 \pm 0.6^{*}$ & $0.7 \pm 0.2^{* * *}$ & $54.9 \pm 0.5$ \\
\hline line 10 & $4.8 \pm 0.0$ & $19.0 \pm 1.0 *$ & $13.0 \pm 0.5^{* * *}$ & $9.6 \pm 0.5^{* * *}$ & $4.7 \pm 1.2^{* *}$ & $46.9 \pm 0.6^{*}$ & $1.2 \pm 0.1^{* * *}$ & $52.8 \pm 1.4$ * \\
\hline line 11 & $4.3 \pm 0.0$ & $16.5 \pm 0.4$ & $16.3 \pm 0.2^{* * *}$ & $5.4 \pm 0.3^{* * *}$ & $3.6 \pm 0.3^{* * *}$ & $51.9 \pm 0.4$ & $0.8 \pm 0.2^{* * *}$ & $56.2 \pm 0.0$ \\
\hline line 12 & $4.1 \pm 0.2$ & $16.3 \pm 0.5$ & $14.1 \pm 0.9^{* * *}$ & $7.7 \pm 1.2^{* *}$ & $1.8 \pm 0.3^{* *}$ & $53.2 \pm 1.0$ & $1.8 \pm 0.2^{* *}$ & $56.7 \pm 1.1$ \\
\hline line 13 & $3.9 \pm 0.3$ & $17.1 \pm 2.1$ & $9.5 \pm 0.2^{* *}$ & $13.3 \pm 0.4$ & $1.2 \pm 0.1^{* *}$ & $51.1 \pm 2.7$ & $2.2 \pm 0.1^{* *}$ & $54.5 \pm 2.7$ \\
\hline line 14 & $4.3 \pm 0.3$ & $16.2 \pm 0.5$ & $20.0 \pm 0.7^{* * *}$ & $1.5 \pm 0.1^{* * *}$ & $0.5 \pm 0.1$ & $56.2 \pm 1.2^{* *}$ & $0.1 \pm 0.0 * * *$ & $56.8 \pm 1.3$ \\
\hline line 15 & $4.0 \pm 0.4$ & $16.1 \pm 0.5$ & $14.2 \pm 1.2^{* * *}$ & $6.6 \pm 0.9^{* * *}$ & $0.5 \pm 0.1$ & $55.5 \pm 0.7^{* *}$ & $1.8 \pm 0.4^{* *}$ & $57.7 \pm 0.8 *$ \\
\hline line 16 & $4.1 \pm 0.1$ & $15.4 \pm 0.4^{* *}$ & $13.4 \pm 1.5^{* *}$ & $8.3 \pm 1.3^{* *}$ & $0.5 \pm 0.1$ & $55.6 \pm 0.2^{* *}$ & $1.7 \pm 0.3^{* *}$ & $57.8 \pm 0.5 *$ \\
\hline $\begin{array}{l}\text { average of } \\
\text { transgenics }\end{array}$ & $4.4 \pm 0.1$ & $20.5 \pm 0.9$ & $15.7 \pm 0.5$ & $5.4 \pm 0.4$ & $7.7 \pm 0.7$ & $44.4 \pm 1.2$ & $0.9 \pm 0.1$ & $53.0 \pm 0.8$ \\
\hline
\end{tabular}

Three or four replicates of 30-seed samples were measured for wild-type and each transgenic line. All data are averages of measurements \pm SD. Fatty acid legend: $18: 1$ is oleic; $18: 2$ is linoleic; $18: 3$ is linolenic; $18: 1 \mathrm{OH}$ is ricinoleic; $20: 1 \mathrm{OH}$ is lesquerolic; and $20: 2 \mathrm{OH}$ is auricolic acid. $^{a}$, total content of five common fatty acids: palmitic (16:0), palmitoleic (16:1), stearic (18:0), arachidic (20:0), and eicosenoic acids (20:1). Two-tailed Student's $t$-test. ${ }^{*} p<0.05 ;{ }^{* *} p<0.01 ;{ }^{* * *} p<0.001$.

In greenhouse-grown plants we produced selfed $\mathrm{T}_{2}$ seeds by hand-pollination of individual Basta-resistant $\mathrm{T}_{1}$ plants. Multiple $\mathrm{T}_{2}$ seed population lines were obtained from each line 1 to line 6 as they contained higher levels of 18:1OH than the remaining lines (Table 1). Results of FA analysis for each $\mathrm{T}_{2}$ line is shown in Figure 2. As in the 
$\mathrm{T}_{1}$ generation, the five minor FAs combined did not show significant changes between WT and each $T_{2}$ transgenic line (Figure 2, Table S2). However, we did not find any $T_{2}$ off-springs containing $18: 1 \mathrm{OH}$ at a level higher than their parents. $\mathrm{T}_{2}$ populations from line 1 and line 2 had substantial reduction in 18:1OH content, from $26.6 \%$ to $19-9 \%$ (line 1-1-1-9) and $16.8 \%$ to $7.3-2.3 \%$ (line 2-1-2-4), respectively, (Figure 2). For line 3 to line 6, similar levels of $18: 1 \mathrm{OH}$ were maintain in their top $\mathrm{T}_{2}$ off-springs, showing $14.6 \%$ (line $3-1$ ), $10.6 \%$ (line $4-1$ ), $9.8 \%$ (line 5-1), and 6.8\% (line 6-1) compared with their $\mathrm{T}_{1}$ parents at $16.6 \%$, $11.7 \%, 10.2 \%$ and $8.5 \%$, respectively, (Figure 2); low levels of $18: 1 \mathrm{OH}$ were observed in line 3-8, line $4-9$, and line $5-8$ and line $6-9$ at 2.6\%, 3.7\%, 1.6\% and 2.9\%, respectively, (Figure 2).

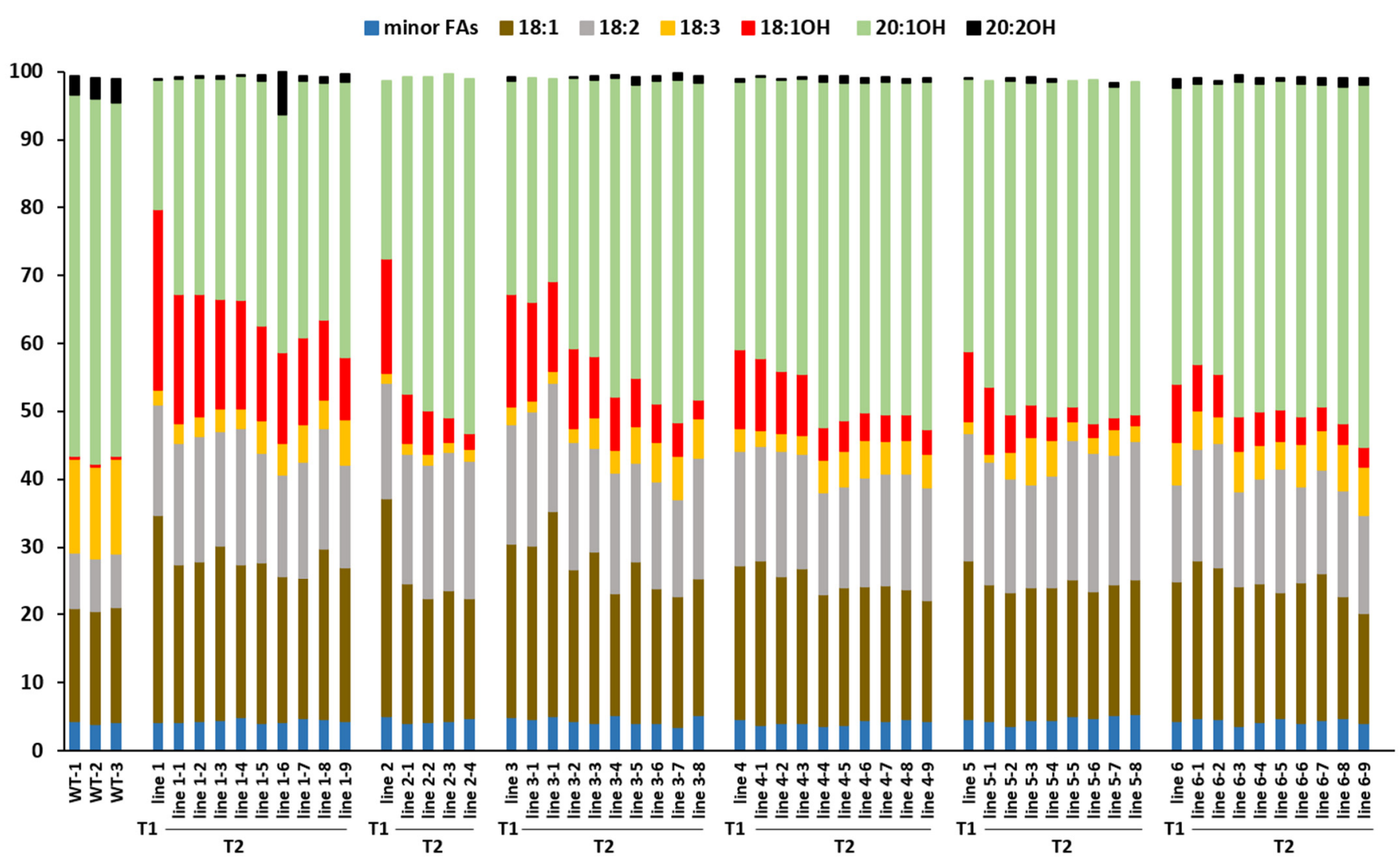

Figure 2. Fatty acid content in T2 seeds expressing AtFAD3 RNAi + CsFAE1 RNAi. Triplicates of 30-seed samples were measured for wild-type (WT) and each transgenic line. Fatty acid legend: 18:1 is oleic; 18:2 is linoleic; 18:3 is linolenic; 18:1OH is ricinoleic; $20: 1 \mathrm{OH}$ is lesquerolic; and $20: 2 \mathrm{OH}$ is auricolic acid. Total content of five common minor fatty acids: palmitic (16:0), palmitoleic (16:1), stearic (18:0), Arachidic acid (20:0), and eicosenoic acid (20:2OH).

\subsection{Changes of FA Composition in Transgenic Lesquerella Expressing Three dsRNAs, CsFAD2 $R N A i+A t F A D 3 R N A i+$ CsFAE1 RNAi}

Fifteen independent transgenic lines expressing the 3-dsRNAs, CsFAD2 RNAi+AtFAD3 RNAi + CsFAE1 RNAi were generated and their $\mathrm{T}_{1}$ seeds were analyzed for FA composition. Once again, the five minor fatty acids, palmitic (16:0), palmitoleic (16:1), stearic (18:0), arachidic (20:0), and eicosenoic (20:1) acids, had slight variation among transgenic lines (Table S3). There was no significant difference on the total minor FAs content between each transgenic line and WT (Table 2). For the other FAs, we observed similar average contents in 18:2, 18:3 and 20:1 between the group expressing 2-dsRNA (AtFAD3 RNAi + CsFAE1 RNAi) (Table 1) and the group expressing 3-dsRNA (Table 2). Noticeably, the 3-dsRNA group with the addition of CsFAD2 RNAi accumulated more $18: 1$ at the average of $27.8 \%$ (Table 2) compared with the average of $20.5 \%$ in the 2 -dsRNA group (Tables 1 and 2). In addition, the increase in average 18:1OH and decrease in av- 
erage total HFA were less dynamic in the 3-dsRNA group, showing averages of $4.7 \%$ and $48.9 \%$, respectively, (Table 2 ), compared with that of $7.7 \%$ and $53 \%$ in lines expressing 2-dsRNA, respectively, (Tables 1 and 2). The fatty acid composition of WT presented in Tables 1 and 2, and Figure 2 are similar to previously described [11]. We did not observe any changes of growth phenotype for all transgenic lesquerella lines.

Table 2. Fatty acid composition (mole \%) in T1 seeds expressing CsFAD2 RNAi + AtFAD3 RNAi + CsFAE1 RNAi.

\begin{tabular}{|c|c|c|c|c|c|c|c|c|}
\hline Line & $\begin{array}{l}\text { Total Minor } \\
\text { Fatty Acid }^{\text {a }}\end{array}$ & $18: 1$ & $18: 2$ & $18: 3$ & 18:1OH & $20: 10 H$ & $20: 2 \mathrm{OH}$ & $\begin{array}{c}\text { Total } \\
\text { Hydroxy } \\
\text { Fatty Acid }\end{array}$ \\
\hline wild-type & $4.2 \pm 0.2$ & $16.7 \pm 0.2$ & $8.0 \pm 0.2$ & $13.7 \pm 0.2$ & $0.40 \pm 0.0$ & $53.0 \pm 0.9$ & $3.1 \pm 0.5$ & $56.5 \pm 0.7$ \\
\hline line 1 & $4.2 \pm 0.1$ & $27.7 \pm 0.3^{* * *}$ & $13.8 \pm 0.4^{* * *}$ & $4.8 \pm 0.5^{* * *}$ & $15.4 \pm 0.7^{* * *}$ & $33.3 \pm 0.8^{* * *}$ & $0.9 \pm 0.1^{* * *}$ & $49.6 \pm 0.1^{* * *}$ \\
\hline line 2 & $4.3 \pm 0.1$ & $26.4 \pm 2.4^{* *}$ & $13.6 \pm 0.3^{* * *}$ & $5.5 \pm 0.8^{* * *}$ & $10.3 \pm 0.9^{* * *}$ & $38.8 \pm 2.5^{* * *}$ & $1.1 \pm 0.1^{* *}$ & $50.1 \pm 1.9^{* *}$ \\
\hline line 3 & $5.2 \pm 0.0^{* * *}$ & $35.7 \pm 1.6^{* *}$ & $15.1 \pm 0.4^{* * *}$ & $3.1 \pm 1.0^{* * *}$ & $8.2 \pm 1.1^{* * *}$ & $32.4 \pm 1.8^{* * *}$ & $0.5 \pm 0.3^{* *}$ & $40.9 \pm 1.1^{* * *}$ \\
\hline line 4 & $4.1 \pm 0.3$ & $22.6 \pm 0.6^{* * *}$ & $15.8 \pm 1.5^{* * *}$ & $4.3 \pm 2.5^{* *}$ & $7.5 \pm 1.0^{* * *}$ & $44.9 \pm 0.7^{* * *}$ & $0.7 \pm 0.6^{* *}$ & $53.2 \pm 1.3^{* *}$ \\
\hline line 5 & $5.4 \pm 0.1^{* * *}$ & $30.2 \pm 1.0^{* * *}$ & $13.2 \pm 1.1^{* * *}$ & $3.8 \pm 0.3^{* * *}$ & $6.5 \pm 0.8^{* * *}$ & $37.3 \pm 1.0^{* * *}$ & $0.7 \pm 0.1^{* * *}$ & $44.5 \pm 1.8^{* * *}$ \\
\hline line 6 & $4.5 \pm 0.0^{*}$ & $35.8 \pm 4.1^{* * *}$ & $15.1 \pm 0.2^{* * *}$ & $5.0 \pm 0.7^{* * *}$ & $6.3 \pm 0.4^{* * *}$ & $35.6 \pm 3.7^{* * *}$ & $0.7 \pm 0.3^{* * *}$ & $42.6 \pm 4.1^{* *}$ \\
\hline line 7 & $4.1 \pm 0.1$ & $17.5 \pm 0.8$ & $17.3 \pm 1.2^{* * *}$ & $3.9 \pm 0.9^{* * *}$ & $6.3 \pm 0.5^{* * *}$ & $50.2 \pm 0.5^{* *}$ & $0.7 \pm 0.0^{* * *}$ & $57.2 \pm 0.6$ \\
\hline line 8 & $4.3 \pm 0.2 *$ & $38.8 \pm 3.5^{* * *}$ & $14.4 \pm 0.9^{* * *}$ & $1.7 \pm 0.3^{* * *}$ & $4.6 \pm 0.3^{* * *}$ & $36.1 \pm 2.8^{* * *}$ & $0 \pm 0.3^{* * *}$ & $40.7 \pm 2.6^{* * *}$ \\
\hline line 9 & $3.9 \pm 0.2$ & $24.6 \pm 2.1^{* *}$ & $13.3 \pm 0.5^{* * *}$ & $6.0 \pm 0.5^{* * *}$ & $1.9 \pm 0.2^{* * *}$ & $48.9 \pm 1.4^{* *}$ & $1.2 \pm 0.2^{* *}$ & $52.1 \pm 1.4^{* *}$ \\
\hline line 10 & $4.5 \pm 0.8$ & $32.3 \pm 2.8^{* * *}$ & $10.7 \pm 1.3^{* * *}$ & $7.1 \pm 1.1^{* * *}$ & $1.1 \pm 0.2^{* * *}$ & $43.1 \pm 2.2^{* *}$ & $1.5 \pm 0.3^{* *}$ & $45.7 \pm 1.8^{* * *}$ \\
\hline line 11 & $4.8 \pm 0.3 *$ & $22.9 \pm 0.8^{* * *}$ & $13.9 \pm 0.1^{* * *}$ & $7.0 \pm 0.7^{* * *}$ & $0.7 \pm 0.1^{* *}$ & $49.7 \pm 0.7^{* *}$ & $0.9 \pm 0.1^{* *}$ & $51.3 \pm 0.6^{* * *}$ \\
\hline line 12 & $4.3 \pm 0.2$ & $28.4 \pm 1.4^{* * *}$ & $16.0 \pm 0.7^{* * *}$ & $3.0 \pm 0.2^{* * *}$ & $0.4 \pm 0.0$ & $47.9 \pm 0.7^{* *}$ & $0.0 \pm 0.0^{* * *}$ & $48.3 \pm 0.7^{* * *}$ \\
\hline line 13 & $4.4 \pm 0.1$ & $22.7 \pm 2.8^{*}$ & $17.4 \pm 0.6^{* * *}$ & $1.9 \pm 0.4^{* * *}$ & $0.4 \pm 0.1$ & $53.2 \pm 2.0$ & $0.0 \pm 0.0^{* * *}$ & $53.6 \pm 2.0$ \\
\hline line 14 & $4.3 \pm 0.3$ & $24.3 \pm 2.0^{* *}$ & $14.6 \pm 1.1^{* * *}$ & $4.5 \pm 0.9^{* * *}$ & $0.4 \pm 0.0$ & $50.9 \pm 1.1^{*}$ & $1.1 \pm 0.5^{* *}$ & $52.4 \pm 1.6^{* *}$ \\
\hline line 15 & $4.0 \pm 0.0^{* * *}$ & $26.3 \pm 1.6^{* * *}$ & $14.5 \pm 0.4^{* * *}$ & $4.0 \pm 0.6^{* * *}$ & $0.4 \pm 0.0$ & $50.1 \pm 0.9^{*}$ & $0.7 \pm 0.2^{* * *}$ & $51.2 \pm 1.0 * *$ \\
\hline $\begin{array}{l}\text { average of } \\
\text { transgenic } \\
\text { line }\end{array}$ & $4.4 \pm 0.4$ & $27.8 \pm 5.9$ & $14.6 \pm 1.7$ & $4.4 \pm 1.6$ & $4.7 \pm 4.5$ & $43.5 \pm 7.2$ & $0.7 \pm 0.4$ & $48.9 \pm 5.0$ \\
\hline
\end{tabular}

Three or four replicates of 30-seed samples were measured for wild-type and each transgenic line. All data are averages of three measurements \pm SD. Fatty acid legend: $18: 1$ is oleic; $18: 2$ is linoleic; $18: 3$ is linolenic; $18: 1 \mathrm{OH}$ is ricinoleic; $20: 1 \mathrm{OH}$ is lesquerolic; and $20: 2 \mathrm{OH}$ is auricolic acid. ${ }^{a}$, total content of five common fatty acids: palmitic (16:0), palmitoleic (16:1), stearic (18:0), arachidic (20:0), and eicosenoic acids (20:1). Two-tailed Student's $t$-test. ${ }^{*} p<0.05 ;{ }^{* *} p<0.01 ;{ }^{* *} p<0.001$.

\subsection{Correlations between FA Levels among Transgenic Lines}

Correlation analysis was performed to show the relationships between FA accumulation for 2-dsRNA group at $\mathrm{T}_{1}$ and $\mathrm{T}_{2}$ generations, and 3-dsRNA group (Table S4). As expected for the impact of CSFAE1 RNAi, strong negative correlations were displayed between 18:1OH and 20:1OH $(-0.99 \leq r \geq-0.75)$ in all groups examined (Table S4). Similarly, for the impact of AtFAD3 RNAi, strong negative correlations between 18:2 and 18:3 $(-0.92 \leq r \geq-0.67)$ were also shown in all groups examined (Table S4). The impact of CsFAD2 RNA $i$ in 3-dsRNA lines exhibited weak negative correlation between 18:1 and 18:2 $(r=-0.38)$ and very weak positive correlation between 18:1 and 18:1OH $(r=0.15)$ (Table S4). For both 2-dsRNA and 3-dsRNA groups, we observed strong negative correlations between total HFA and 18:1 $(-0.82 \leq r \geq-0.92)$, and strong positive correlations between total HFA and 20:1OH (0.75 $\leq r \geq 0.96)$ (Table S4).

\section{Discussion}

3.1. High Levels of 18:1OH Accumulate in Lesquerella by Blocking Elongation and Desaturation of Fatty Acids

In this study, the dsRNA fragments in AtFAD3 RNAi and CsFAE1 RNAi contain a 323 bp or 251 bp sequence sharing $91.7 \%$ and $82.8 \%$ identity with lesquerella PfFAD3-1 (BenBank ID: MF611845) [32] and PfKCS18 (GenBank ID: AF367052) [27], respectively. When the 2-dsRNAs (AtFAD3 RNAi and CsFAE1 RNAi) were introduced to lesquerella, we observed changes in FA composition (Table 1). Among the $16 \mathrm{~T}_{1}$ transgenic lesquerella lines, 15 lines shifted the accumulation of 18:3 to 18:2, showing a strong negative correlation between 18:2 and 18:3 ( $r=0.93$ ) (Table S4); 13 lines shifted 20:1OH to 18:1OH, which also displayed a strong negative correlation $(r=-0.99)$ (Table S4). These results indicate 
that AtFAD3 RNAi and CSFAE1 RNAi are effective in silencing PfFDA3-1 and PfKCS18, respectively. To see the effect of AtFAD3 RNAi and CsFAE1 RNA $i$ in the next generation, we examined FA composition in $\mathrm{T}_{2}$ seeds from the top six $\mathrm{T}_{1}$ lines. The line 1 seeds produced the highest $18: 1 \mathrm{OH}$ content at $26.6 \%$ in the $\mathrm{T}_{1}$ generation, however, the $18: 1 \mathrm{OH}$ decreased from $19 \%$ (line 1-1) to $9 \%$ (line 1-9) in the $\mathrm{T}_{2}$ generation (Figure 2). Similar significant reduction of 18:1OH also occurred in line 2 from $16.8 \%\left(\mathrm{~T}_{1}\right)$ to $7.3 \%\left(\mathrm{~T}_{2}\right.$ line $\left.2-1\right)$ to $2.3 \%\left(\mathrm{~T}_{2}\right.$ line 2-4). The remaining top best $\mathrm{T}_{2}$ off-springs from line 3 to line 6 also showed reductions in $18: 1 \mathrm{OH}$ contents, but the reductions were not as large, varying between line 3 from $11.7 \%\left(\mathrm{~T}_{1}\right)$ to $10.57 \%\left(\mathrm{~T}_{2}\right.$ line 3-1) and line 6 from $8.5 \%\left(\mathrm{~T}_{1}\right)$ to $6.8 \%$ ( $\mathrm{T}_{2}$ line 6-1). The reduction of 18:1OH content occurring in all 6 top $\mathrm{T}_{2}$ lines implies that the competence of CsFAE1 RNAi was not fully transmitted to the next generation. A similar phenomenon was reported for an $R N A i$ in arabidopsis where the influence of the silencing faded through several selfed generations due to a generation-dependent decrease in transcription of the RNAi [59]. In maize, analysis of an RNAi effect over multiple generations also reveals that some lines display reduced transgene silencing, but the effect of the RNAi can be maintained by outcrossing rather than self-pollination [60]. Such phenomenon is explained based on the assumption that hemizygosity would reduce any potential trans-interactions between the transgenes on homologous chromosomes that could lead to transgene silencing [60]. The molecular basis of CsFAE1 RNAi stability in lesquerella remains to be investigated. Another possibility is that the $18: 1 \mathrm{OH}$ contents in these transgenic lesquerella lines resulted from equilibrium of FA and TAG metabolism, and there could be a ceiling for 18:1OH accumulation in lesquerella. We generated 31 independent lines expressing CsFAE1 RNAi (Tables 1 and 2), only one line accumulated a high level of $18: 1 \mathrm{OH}$ at $26.6 \%$ and it dropped to $19 \%$ in the next generation (Table 1 ). The second highest three lines contain 18:1OH ranging from 15-17\% (Tables 1 and 2). Thus, a highest stable equilibrium of 18:1OH level could fall between $15-20 \%$. These lines are useful for further assessment of 18:1OH accumulation limits and relationships between CSFAE1 $R N A i$ effect and 18:1OH levels in lesquerella. Assuming the silencing effects of CsFAE1 $R N A i$ and AtFAD3 RNAi led to increases in 18:1OH and decreases in 18:3, respectively, there were 24 out of $31(77 \%)$ of the transgenic lines with increased 18:1OH levels, whereas 30 out of 31 (97\%) of the lines showed decreased 18:3 content (Tables 1 and 2). The results indicate that the silencing effect of AtFAD3 RNAi is more stable than that of CsFAE1 RNAi, which could be attributed to the higher nucleotide identity of $91.7 \%$ displayed between AtFAD3 RNAi and PfFAD3-1 than the 82.8\% identity demonstrated between CsFAE1 RNAi and PfKCS18.

In a separate experiment, we introduced a construct carrying three dsRNAs, AtFAD3 RNAi + CsFAE1 RNAi + CsFAD2 RNAi into lesquerella and generated 15 independent transgenic lines. We observed strong negative correlation between 18:2 and 18:3 $(r=-0.67)$, and between $18: 1 \mathrm{OH}$ and $20: 1 \mathrm{OH}(r=-0.75)$, indicating the strong impacts of AtFAD3 RNAi and CsFAE1 RNAi shown again in transgenics expressing the 3-dsRNAs construct (Table 2 and Table S4). Regarding the effect of CsFAD2 RNAi, we observed a weak negative correlation between 18:1 and 18:2 $(r=-0.38)$, but this is opposite to the weak positive correlation between 18:1 and 18:2 $(r=0.38)$ observed in the 2-dsRNAs which did not contain CsFAD2 RNAi (Table S4). The result suggests that CsFAD2 RNAi exerts certain silencing effect which resulted in shifting the accumulation of 18:2 to 18:1 in lesquerella. Unlike PfFAD3-1 and PfKCS18 which were specifically targeted by AtFAD3 RNAi and CSFAE1 RNAi, respectively, the CSFAD2 RNAi may target two homologous lesquerella genes, PfFAD2 (GenBank ID: DQ518313) and PfFAH12 (GenBank ID: KC972619) that share $78.3 \%$ nucleotide identity. In fact, the dsRNA fragment in CsFAD2 RNAi contains $299 \mathrm{bp}$ sequences which exhibit $55.7 \%$ and $88.9 \%$ identity with PfFAD2 and PfFAH12, respectively. The effect of CsFAD2 RNAi on silencing PfFAH12 can be inferred by the reduction of correlation strength between 18:1 and 18:1OH from very strong positive $(r=0.93)$ in 2-dsRNAs lines, which did not express CsFAD2 RNAi (Table 1 and Table S4), to very weak positive $(r=0.15)$ in 3-dsRNA lines due to CsFAD2 RNAi (Table 2 and Table S4). The shift 
of $18: 1 \mathrm{OH}$ accumulation to $18: 1$ was also evident by lower accumulation of $18: 1 \mathrm{OH}$ at an average of $4.4 \%$ in the 3-dsRNAs lines compared with that of $7.7 \%$ (average) in the 2-dsRNAs lines (Tables 1 and 2). The silencing effect of CsFAD2 RNAi on both PfFAD2 and PfFAH12 gene expression can be deduced by the increased accumulation of 18:1 content at an average of $27.8 \%$ in lines expressing 3-dsRNAs (Table 2) compared with that of $20.5 \%$ in lines expressing 2-dsRNAs (Table 1). Our results support previous observations of using these $R N A i$ sequences to generate high 18:1 content in camelina lines, including CsFAD2 RNAi [56], CsFAD2 RNAi + CsFAE1 RNAi [57], or CsFAD2 RNAi + AtFAD3 RNAi + CsFAE1 $R N A i$ [58] (in preparation).

\subsection{Constrains and Potential for Production of a High 18:1OH-Containing Oil in Lesquerella}

Expression of CsFAE1 RNAi, CsFAD2 RNAi, and AtFAD3 RNAi in lesquerella resulted in significant increases not only in 18:1OH, but also in 18:1 (Tables 1 and 2). The results indicated that 18:1 was inefficiently used for synthesizing 18:1OH. This could be partially due to the nature of PfFAH12 which is a bifunctional oleate hydroxylase:desaturase [25], that may not efficiently convert 18:1 to $18: 1 \mathrm{OH}$. Seed oil from castor or Physaria lindheimeri contains 90\% 18:10H [61] or 85\% 20:1OH [62], respectively. These species have distinct FAH12s, RcFAH12 in castor [24] and PlFAH12 in P. lindheimeri [62]. Replacement of PfFHA12 with RcFAH12 or PlFAH12 should allow more efficient 18:1OH synthesis in lesquerella. Alternatively, the resulted substantial accumulation of 18:1 could also be due to some lesquerella endogenous genes having substrate preference to 18:1 and efficiently incorporating 18:1 into TAG. During seed development, a lesquerella LPAT acts like a typical plant LPAT that has substrate preference for unsaturated FAs including18:1-CoA, resulting in efficient incorporation of 18:1-CoA into TAG through the Kennedy pathway. Castor RcLPAT2 is useful for increasing 18:1OH at the $s n-2$ of TAGs in lesquerella [15,37]. Additional isoforms, RCLPAT3B and RCLPATB, have also been shown to increase $18: 1 \mathrm{OH}$ in arabidopsis seed TAGs [52]. Substituting the lesquerella endogenous PfLPAT with these specific castor RcLPATs may increase 18:1OH flux to TAG by RcLPATs. Besides the Kennedy pathway, PCderived DAG pathway may also channel 18:1 into TAG by a lesquerella PfPDCT (Figure 1). Once 18:1-PC is synthesized, e.g., by PfLPCAT, some of the 18:1-PC could be converted by PDCT to 18:1-DAG for TAG assembly (Figure 1). Lesquerella seed TAGs contain about 21\% PUFAs (18:2 and 18:3) (Tables 1 and 2). There is strong evidence that plants enriched with PUFAs in seed TAG may use the PC-derived pathway [19]. Therefore, it is likely that PC-derived DAGs are utilized in TAG assembly in lesquerella. Castor gene RcPDCT was demonstrated to enhance flux from 18:10H-PC to 18:1OH-DAG [41]. It would be favorable to over-express RcPDCT in lesquerella to increase 18:1OH incorporation to TAG through PC-derived DAG pathway.

It is anticipated that the increased $18: 1 \mathrm{OH}$ is at the expense of $20: 1 \mathrm{OH}$ in transgenic lesquerella lines expressing CSFAE1 RNAi (Tables 1 and 2), however, total HFA decreased and showed strong correlation with $20: 1 \mathrm{OH}$ contents $(0.96<r>0.75$, Table S4). The results indicated that $18: 1 \mathrm{OH}$ was not incorporated into TAG at the same efficiency as 20:1OH. Lesquerella PfKCS18 is evolved to specifically elongate 18:1OH-CoA to 20:1OHCoA [27] (Figure 1). It is possible that other lesquerella enzymes, such as PfGPAT, PfDGAT and/or PfPDAT also co-evolved to adapt and utilize 20:1OH efficiently. Most plant GPATs have a broad acyl-CoA substrate specificity $[19,63]$. There is evidence that castor RcGPAT9 plays an important role in acylating HFAs at the $s n-1$ position of G3P, resulting in sn-1-HFALPA, which facilitates the subsequent incorporation of $s n-2$ and $s n-3$ HFA into seed TAG by LPAT and DGAT [53]. In plant seeds accumulating unusual FAs, members of DGAT2 family are essential enzymes in acylating unusual FAs to the $s n-3$ position of DAG. For example, castor RcDGAT2 prefers 18:1OH to common FAs [50,64]. Lesquerella seed transcriptome analysis reveals one PfGPAT9 and three PfDGATs [17]. It would be interesting to explore whether these genes have substrate selectivity for HFA-CoA or common FA-CoA. The role of PfKCS18 has been explored in camelina [65]. Transgenic camelina expressing RcFAH12 accumulates 15\% HFA [66] but the resulted transgenic seeds reduce TAG content 
and seed germination ability [65]. When RcFAH12 with PfKCS18 are co-expressed, the transgenic camelina seeds increase HFA content to $21 \%$ and also restore TAG content and seed germination ability [65]. Camelina is not a native species for HFA synthesis, 18:1OHPC generated by RcFAH12 in camelina may be subjected to $\beta$-oxidation [67], or represents a bottleneck [40], limiting HFA accumulation. The elongation step by PfKCS18 may ease the 18:1OH flux from PC to cytosol FA-CoA pool, thus relieve the bottleneck and facilitate the utilization of HFA-CoA by the Kennedy pathway [33] (Figure 1). PDAT transfer FA at the $s n-2$ position of PC to the $s n-3$ position of DAG, yielding TAG [44,68] (Figure 1). Castor has two PDAT1s, but only RcPDAT1-2 (or RcPDAT1A) selects 18:10H-PC as substrate, and it participates in HFA-TAG synthesis $[45,46]$. There are three PfPDATs expressed in lesquerella seeds [17]. Whether these PfPDATs are involved in transferring HFA-PC to DAG remains to be investigated. To further enhance 18:1OH accumulation in lesquerella TAGs, coordinated expression of multiple genes, such as RcGPAT9, RcDGAT2 and RcPDAT1-2 (or RcPDAT1A) should promote 18:10H accumulation in seed TAG.

In summary, to develop a castor oil-producing lesquerella crop, we designed genetic engineering schemes based on known pathways of fatty acid biosynthesis in lesquerella. As predicted, high levels of $18: 1 \mathrm{OH}$ were accumulated by reducing the elongation of $18: 1 \mathrm{OH}$ to $20: 1 \mathrm{OH}$ through expression of CSFAE1 RNAi. Additionally, high levels of 18:1 and 18:2 were accumulated through suppression of desaturation steps by expressing CsFAD2 RNA $i$ and/or AtFAD3 RNAi. Intriguingly, the accumulated 18:1 was not efficiently utilized to produce 18:1OH and instead, 18:1 was largely channeled to seed TAG. On the other hand as discussed, multiple mechanisms could limit the acylation of 18:1OH into TAG. Our results direct future research efforts in implementing genetic approach that targets not only enhancement of 18:1OH synthesis, but also on increased 18:1OH acylation to TAG. Nevertheless, we demonstrated for the first time that lesquerella can be engineered for large increases in 18:1OH levels from $0.4-0.5 \%$ in WT to a stable high level of $15-20 \%$ in transgenic seed oils.

\section{Materials and Methods}

4.1. Construction of pBinGlyBar1 + AtFAD3 RNAi + CsFAE1 RNAi and pBinGlyBar1 CsFAD2 $R N A i+A t F A D 3 R N A i+C s F A E 1 R N A i$

Constructs used for transformation experiments were prepared as follows. The FAD3 $R N A i$ hairpin cassette was prepared by PCR amplification of a 323-bp fragment of the FAD3 gene from Arabidopsis thaliana Col-0 cDNA in both antisense using primers Arm15'NheI-F3 5'- AATAAGCTAGCACCGGACACACCACCAGAAC-3' and Arm1-3'EcoRIF3 5' - TATTGAATTCCGTAGACTTTAAGAACCGCGAG-3' and sense orientations using primers Arm2-5'PstI-F3 5' - TAATACTGCAGCACCGGACACACCACCAGAAC-3' and Arm2-3'XhoI-F3 5'- ATTACTCGAGCCGTAGACTTTAAGAACCGCGAG-3' and cloned into plasmid pGEMT-Easy-HTM3 [69], replacing the existing antisense and sense arms. The resulting FAD3 hairpin sequence was excised at EcoRI/XhoI from that plasmid and inserted into pBinGlyBar1 [59] as an EcoRI/XhoI fragment. Flanking the FAD3 hairpin sequence in pBinGlyBar1 was the seed-specific promoter and the $3^{\prime} \mathrm{UTR}$ for the Glycine max glycinin-1 gene. The new construct was designated pBinGlyBar1 + AtFAD3 RNAi. The FAE1 RNAi suppression cassette was prepared by PCR amplification of a 251-bp portion of the camelina FAE1 gene from cDNA using the oligonucleotides: $5^{\prime}-$ TAATTCTAGACTCGAGGGGAATACTTCGTCTAGCTC-3' ${ }^{\prime}$ and $5^{\prime}$-TATAAAGCTTACTAGT CCGACCGTTTTTTGACATGAGTC-3'. The PCR product was assembled sequentially in an inverted repeat orientation of either side of the Flaveria trinervia pyruvate orthophosphate dikinase (Pdk) intron [70]. The hairpin cassette was then cloned downstream of the seed-specific promoter for the Glycine max glycinin-1 gene and upstream of the $3^{\prime} \mathrm{UTR}$ for the glycinin-1 gene as a Not 1 fragment. The resulting vector contained AscI restriction sites that flanked the glycinin-1 promoter and $3^{\prime} U T R$. Using this restriction site the entire cassette containing promoter, RNAi hairpin and $3^{\prime}$ UTR were assembled into the AscI site of the binary vector pBinGlyBar1 + AtFAD3 RNAi. The resulting construct was designated pBinGlyBar1 + AtFAD3 RNAi + cFAE1 RNAi. The FAD2 RNAi hairpin cassette was pre- 
pared by PCR amplification of a 299-bp portion of the camelina FAD2 gene from cDNA using the oligonucleotides:5'-TAATTCTAGACTCGAGCGTCTTGATCACTTACTTGCAG-3' and $5^{\prime}$-TATAAAGCTTACTAGTCTACATAGATACACTCCTTTGCC- $3^{\prime}$. The product was cloned sequentially in an inverted repeat orientation of either side of the Flaveria trinervia pyruvate orthophosphate dikinase (Pdk) intron. The hairpin cassette was then cloned downstream of the seed-specific promoter for the soybean oleosin gene and upstream of the oleosin $3^{\prime}$ UTR as a Not 1 fragment. The resulting vector contained AscI restriction sites that flanked the oleosin promoter and $3^{\prime} U T R$. Using this restriction site the entire cassette containing promoter, RNAi hairpin and $3^{\prime} \mathrm{UTR}$ were assembled into the $M l u \mathrm{I}$ site of pBinGlyBar1 + AtFAD3 RNAi + cFAE1 RNAi to make pBinGlyBar1 + AtFAD3 RNAi + cFAE1 RNAi + cFAD2 RNAi which also contains a bar marker gene for Basta selection of transgenic plants.

\subsection{Plant Transformation and Growth Condition}

The lesquerella seeds, WCL-LY2 [71] were kindly provided by Dave Dierig (USDAARS, Arid-Land Agricultural Research Center, Maricopa, AZ, USA). Plant transformation was performed using the Agrobacterium tumefaciens strain AGL1 [72] carrying the binary vector $p$ Bin GlyBar1 + AtFAD3 RNAi + CsFAE1 RNAi and pBinGlyBar1 CsFAD2 RNAi + AtFAD3 RNAi + CsFAE1RNAi. Tissue culture and plant growth conditions were as described before [14] with the exception of using Basta (1 mg/L) as a transgenic selective agent. In brief, leaves harvested from plants in sterile condition were wounded by slightly scratching the underside of the leaf and then dipping the leaf in the half strength MS medium containing the Agrobacterium for $5 \mathrm{~min}$. Following the inoculation, leaves were blotted on sterilized filter paper and transferred to Callus and Shoot Induction (CSI) medium composed of basal medium (BM, half strength MS medium plus $30 \mathrm{~g} \mathrm{~L}^{-1}$ sucrose and $6 \mathrm{~g} \mathrm{~L}^{-1}$ agar, $\mathrm{pH}$ 5.7) supplemented with $1 \mathrm{mg} \mathrm{L}^{-1}$ 6-benzylaminopurine (BA) and $0.1 \mathrm{mg} \mathrm{L}^{-1} 1$-Naphthaleneacetic Acid (NAA). After incubating the infected leaves in the growth chamber for 2 days, the leaves were cut into $5 \mathrm{~mm}$ segments and cultured on CSI media plus $1 \mathrm{mg} \mathrm{L}^{-1}$ Basta for transgenic selection and $100 \mathrm{mg} \mathrm{L}^{-1}$ timentin for inhibiting the Agrobaterium growth. In 6-8 weeks, yellow-greenish Basta resistant calli started to appear on the leaf segments. To eliminate chimeras, each shoot was cut into small pieces (about $2 \times 2 \mathrm{~mm}^{2}$ ) and placed on the CSI medium for shoot regeneration. After 4 rounds of successive regenerations, shoots were sub-cultured on BM plus $1 \mathrm{mg} \mathrm{L}^{-1} \mathrm{BA}, 1 \mathrm{mg} \mathrm{L}^{-1}$ Indole-3-Butyric Acid (IBA) and $1 \mathrm{mg} \mathrm{L}^{-1}$ Basta for multiplication. Shoots $10-15 \mathrm{~mm}$ in length were transferred to rooting medium (BM plus $1 \mathrm{mg} \mathrm{L}^{-1}$ IBA and $50 \mathrm{mg} \mathrm{L}^{-1}$ Basta). When a shoot developed 2-3 roots (usually in 3-5 weeks), it was then transferred to a Magenta box (Sigma, St. Louis, Mo) containing sterilized peat-vermiculite growth mixture (Sunshine mix \#4, Planet Natural, Bozeman, MT) presoaked with $1 \mathrm{mg} \mathrm{L}^{-1}$ IBA water solution. After 8-10 weeks in the growth mixture, well-developed primary plants showing 8-12 normal leaves and 2-3 inch height were transferred to a 6-inch pot and placed under a transparent plastic cover for the first 2 weeks for acclimation in the greenhouse. $\mathrm{T}_{1}$ selfed seeds were obtained by hand-pollination between different flowers from the same transgenic plant $\left(T_{0}\right)$. To estimate the number of transgene locus for each line, $T_{1}$ seeds were germinated on germination medium containing Basta at $1 \mathrm{mg} \mathrm{L}^{-1}$ for 3 weeks. Healthy seedlings showing normally developed cotyledons and 2-4 true leaves were counted as resistance seedlings (R); sensitive seedlings (S) had arrested yellow cotyledons and no true leaves. Transgene locus numbers were based on the Mendelian ratio of R:S, 3:1 for one locus, 16:1 for two loci. $\mathrm{T}_{1}$ seedlings were transplanted into soil for $\mathrm{T}_{2}$ seed production.

\subsection{Analysis of Fatty Acid Composition}

Seeds homogenized in a gas chromatograph (GC) autosampler vial were subjected to direct transesterification to produce fatty acid methyl esters (FAMEs) using trimethylsulphonium hydroxide (TMSH) as described [59,73]. The resulting FAMES were analyzed by GC-flame ionization detection using previously described instrument conditions [74]. 
Supplementary Materials: The following are available online at https:/ /www.mdpi.com/article/ 10.3390 / plants10061093/s1, Table S1: Estimated number of transgene locus for each transgenic line ( $\mathrm{T}_{1}$ seeds), Table $\mathrm{S} 2$ : Fatty acid composition (mole $\%$ ) in $\mathrm{T}_{1}$ seeds expressing AtFAD3 RNAi + CsFAE1 RNAi, Table S3: Fatty acid composition (mole\%) in $\mathrm{T}_{1}$ seeds expressing CsFAD2 RNAi+AtFAD3 $R N A i+$ CsFAE1 RNAi; Table S4: Correlations between the fatty acids among transgenic lines.

Author Contributions: K.J., T.J.N. and E.M. performed the experiments; T.J.N. and G.P. analyzed the data; G.Q.C. and E.B.C. designed the experiments and wrote the manuscript. All authors have read and agreed to the published version of the manuscript.

Funding: This study was supported in part by the U.S. Department of Agriculture Current Research Information System Project 2030-21410-021-00D (to GQC). Research in the EBC lab was supported by National Science Foundation Plant Genome Program (award 1339385) and USDA Hatch funding provided by the Nebraska Agricultural Experiment Station

Institutional Review Board Statement: Not applicable.

Informed Consent Statement: Not applicable.

Data Availability Statement: Not applicable.

Acknowledgments: USDA is an equal opportunity provider and employer. Mention of a specific product name by the U.S. Department of Agriculture does not constitute an endorsement and does not imply a recommendation over other suitable products.

Conflicts of Interest: The authors declare no conflict of interest.

\section{References}

1. Caupin, H.J. Products from castor oil: Past, present and future. In Lipid Technologies and Applications; Gunstone, F.D., Padley, F.B., Eds.; Marcel Dekker: New York, NY, USA, 1997.

2. Patel, V.R.; Dumancas, G.G.; Viswanath, L.C.K.; Maples, R.; Subong, B.J.J. Castor Oil: Properties, Uses, and Optimization of Processing Parameters in Commercial Production. Lipid Insights 2016, 9, 1-12. [CrossRef] [PubMed]

3. Chen, G.Q.; He, X.; McKeon, T.A. A simple and sensitive assay for distinguishing the expression of ricin and Ricinus communis agglutinin genes in developing castor seed (R. communis L.). J. Agric. Food Chem. 2005, 53, 2358-2361. [CrossRef] [PubMed]

4. Lord, M.J.; Jolliffe, N.A.; Marsden, C.J.; Pateman, C.S.C.; Smith, D.C.; Spooner, R.A.; Watson, P.D.; Roberts, L.M. Ricin: Mechanisms of cytotoxicity. Toxicol. Rev. 2003, 22, 53-64. [CrossRef] [PubMed]

5. Chen, G.Q.; He, X.; Liao, L.P.; McKeon, T.A. 2S albumin gene expression in castor plant (Ricinus communis L.). J. Am. Oil Chem. Soc. 2004, 81, 867-872. [CrossRef]

6. Machado, O.L.T.; Silva, J.G., Jr. An allergenic 2 S storage protein from Ricinus communis seeds which is a part of the $2 \mathrm{~S}$ albumin precursor predicted by C-DNA data. Braz. J. Med Biol. Res. 1992, 25, 567-582.

7. Youle, R.J.; Huang, A.H.C. Albumin Storage Proteins in the Protein Bodies of Castor Bean. Plant Physiol. 1978, 61, 13-16. [CrossRef] [PubMed]

8. Roetheli, J.C.; Carlson, K.D.; Kleiman, R.; Thompson, A.E.; Dierig, D.; Glaser, L.K.; Blase, M.G.; Goodell, J. Lesquerella as a Source of Hydroxy Fatty Acids for Industrial Products; Growing Industrial Materials Series; USDA CSRS: Washington, DC, USA, 1991. Available online: https://www.ars.usda.gov/ARSUserFiles/53442010/NewCrops/Lesquerella/PDF/LesquerellaBooklet.pdf (accessed on 27 May 2021).

9. Hayes, D.G.; Carlson, K.D.; Kleiman, R. The isolation of hydroxy acids from lesquerella oil lipolysate by a saponification/extraction technique. J. Am. Oil Chem. Soc. 1996, 73, 1113-1119. [CrossRef]

10. Isbell, T.A.; Mund, M.S.; Evangelista, R.L.; Dierig, D.A. Method for analysis of fatty acid distribution and oil content on a single Lesquerella fendleri seed. Ind. Crop. Prod. 2008, 28, 231-236. [CrossRef]

11. Chen, G.Q.; Lin, J.T.; Lu, C. Hydroxy fatty acid synthesis and lipid gene expression during seed development in Lesquerella fendleri. Ind. Crop. Prod. 2011, 34, 1286-1292. [CrossRef]

12. Dierig, D.A.; Wang, G.; McCloskey, W.B.; Thorp, K.R.; Isbell, T.A.; Ray, D.T.; Foster, M.A. Lesquerella: New crop development and commercialization in the U.S. Ind. Crop. Prod. 2011, 34, 1381-1385. [CrossRef]

13. Von Cruz, M.V.; Dierig, D.A. Germplasm improvement to develop commercially viable lines of the new oilseed crop lesquerella. In Industrial Crops: Breeding for Bioenergy and Bioproducts; Springer: New York, NY, USA, 2015; pp. 315-334. [CrossRef]

14. Chen, G.Q. Effective reduction of chimeric tissue in transgenics for the stable genetic transformation of lesquerella fendleri. HortScience 2011, 46, 86-90. [CrossRef]

15. Chen, G.Q.; van Erp, H.; Martin-Moreno, J.; Johnson, K.; Morales, E.; Browse, J.; Eastmond, P.J.; Lin, J.T. Expression of castor LPAT2 enhances ricinoleic acid content at the sn-2 position of triacylglycerols in lesquerella seed. Int. J. Mol. Sci. 2016, 17, 507. [CrossRef] [PubMed] 
16. Li-Beisson, Y.; Shorrosh, B.; Beisson, F.; Andersson, M.X.; Arondel, V.; Bates, P.D.; Baud, S.; Bird, D.; DeBono, A.; Durrett, T.P.; et al. Acyl-Lipid Metabolism. Arab. Book Am. Soc. Plant Biol. 2013, 11, e0161. [CrossRef] [PubMed]

17. Kim, H.U.; Chen, G.Q. Identification of hydroxy fatty acid and triacylglycerol metabolism-related genes in lesquerella through seed transcriptome analysis. BMC Genom. 2015, 16, 230. [CrossRef]

18. Chen, G.Q.; Kim, W.N.; Johnson, K.; Park, M.E.; Lee, K.R.; Kim, H.U. Transcriptome Analysis and Identification of Lipid Genes in Physaria lindheimeri, a Genetic Resource for Hydroxy Fatty Acids in Seed Oil. Int. J. Mol. Sci. 2021, 22, 514. [CrossRef]

19. Bates, P.D. Understanding the control of acyl flux through the lipid metabolic network of plant oil biosynthesis. Biochim. Biophys. Acta Mol. Cell Biol. Lipids 2016, 1861, 1214-1225. [CrossRef] [PubMed]

20. Lager, I.; Yilmaz, J.L.; Zhou, X.R.; Jasieniecka, K.; Kazachkov, M.; Wang, P.; Zou, J.; Weselake, R.; Smith, M.A.; Bayon, S.; et al. Plant acyl-CoA:lysophosphatidylcholine acyltransferases (LPCATs) have different specificities in their forward and reverse reactions. J. Biol. Chem. 2013, 288, 36902-36914. [CrossRef]

21. Lands, W.E. Lipid Metabolism. Annu. Rev. Biochem. 1965, 34, 313-346. [CrossRef]

22. Bafor, M.; Smith, M.A.; Jonsson, L.; Stobart, K.; Stymne, S. Ricinoleic acid biosynthesis and triacylglycerol assembly in microsomal preparations from developing castor-bean (Ricinus communis) endosperm. Biochem. J. 1991, 280, 507-514. [CrossRef]

23. Moreau, R.A.; Stumpf, P.K. Recent Studies of the Enzymic Synthesis of Ricinoleic Acid by Developing Castor Beans. Plant Physiol. 1981, 67, 672-676. [CrossRef]

24. Van De Loo, F.J.; Broun, P.; Turner, S.; Somerville, C. An oleate 12-hydroxylase from Ricinus communis L. is a fatty acyl desaturase homolog. Proc. Natl. Acad. Sci. USA 1995, 92, 6743-6747. [CrossRef]

25. Broun, P.; Boddupalli, S.; Somerville, C. A bifunctional oleate 12-hydroxylase: Desaturase from Lesquerella fendleri. Plant J. 1998, 13, 201-210. [CrossRef]

26. Bayon, S.; Chen, G.; Weselake, R.J.; Browse, J. A small phospholipase A2- $\alpha$ from castor catalyzes the removal of hydroxy fatty acids from phosphatidylcholine in transgenic Arabidopsis seeds. Plant Physiol. 2015, 167, 1259-1270. [CrossRef] [PubMed]

27. Moon, H.; Smith, M.A.; Kunst, L. A condensing enzyme from the seeds of Lesquerella fendleri that specifically elongates hydroxy fatty acids. Plant Physiol. 2001, 127, 1635-1643. [CrossRef]

28. Okuley, J.; Lightner, J.; Feldmann, K.; Yadav, N.; Lark, E.; Browse, J. Arabidopsis FAD2 gene encodes the enzyme that is essential for polyunsaturated lipid synthesis. Plant Cell 1994, 6, 147. [CrossRef]

29. Arondel, V.; Lemieux, B.; Hwang, I.; Gibson, S.; Goodman, H.M.; Somerville, C.R. Map-based cloning of a gene controlling omega-3 fatty acid desaturation in Arabidopsis. Science 1992, 258, 1353-1355. [CrossRef] [PubMed]

30. Engeseth, N.; Stymne, S. Desaturation of oxygenated fatty acids in Lesquerella and other oil seeds. Planta 1996, 198, 238-245. [CrossRef]

31. Reed, D.W.; Taylor, D.C.; Covello, P.S. Metabolism of hydroxy fatty acids in developing seeds in the genera Lesquerella (Brassicaceae) and Linum (Linaceae). Plant Physiol. 1997, 114, 63-68. [CrossRef]

32. Lee, K.-R.; Kim, E.-H.; Jeon, I.; Lee, Y.; Chen, G.Q.; Kim, H.U. Lesquerella FAD3-1 gene is responsible for the biosynthesis of trienoic acid and dienoic hydroxy fatty acids in seed oil. Ind. Crop. Prod. 2019, 134, 257-264. [CrossRef]

33. Kennedy, E.P. Biosynthesis of complex lipids. Fed. Proc. 1961, 20, 934-940. [PubMed]

34. Hayes, D.G.; Kleiman, R. 1,3-specific lipolysis of lesquerella fendleri oil by immobilized and reverse-micellar encapsulated enzymes. J. Am. Oil Chem. Soc. 1993, 70, 1121-1127. [CrossRef]

35. Lin, J.-T.; Chen, G.Q. Quantification of the Molecular Species of TAG and DAG in Lesquerella (Physaria fendleri) Oil by HPLC and MS. J. Am. Oil Chem. Soc. 2014, 91, 1417-1424. [CrossRef]

36. Lin, J.-T.; Fagerquist, C.K.; Chen, G.Q. Ratios of Regioisomers of the Molecular Species of Triacylglycerols in Lesquerella (Physaria fendleri) Oil Estimated by Mass Spectrometry. J. Am. Oil Chem. Soc. 2016, 93, 183-191. [CrossRef]

37. Chen, G.Q.; Lin, J.-T.; van Erp, H.; Johnson, K.; Lu, C. Regiobiochemical analysis reveals the role of castor LPAT2 in the accumulation of hydroxy fatty acids in transgenic lesquerella seeds. Biocatal. Agric. Biotechnol. 2020, 25, 101617. [CrossRef]

38. Frentzen, M. Acyltransferases from basic science to modified seed oils. Fett 1998, 100, 161-166. [CrossRef]

39. Lu, C.; Xin, Z.; Ren, Z.; Miquel, M.; Browse, J. An enzyme regulating triacylglycerol composition is encoded by the ROD1 gene of Arabidopsis. Proc. Natl. Acad. Sci. USA 2009, 106, 18837-18842. [CrossRef] [PubMed]

40. Bates, P.D.; Browse, J. The pathway of triacylglycerol synthesis through phosphatidylcholine in Arabidopsis produces a bottleneck for the accumulation of unusual fatty acids in transgenic seeds. Plant J. 2011, 68, 387-399. [CrossRef]

41. Hu, Z.; Ren, Z.; Lu, C. The phosphatidylcholine diacylglycerol cholinephosphotransferase is required for efficient hydroxy fatty acid accumulation in transgenic Arabidopsis. Plant Physiol. 2012, 158, 1944-1954. [CrossRef]

42. Slack, C.R.; Campbell, L.C.; Browse, J.A.; Roughan, P.G. Some evidence for the reversibility of the cholinephosphotransferasecatalysed reaction in developing linseed cotyledons in vivo. Biochim. Biophys. Acta Lipids Lipid Metab. 1983, 754, 10-20. [CrossRef]

43. Aryal, N.; Lu, C. A Phospholipase C-Like Protein From Ricinus communis Increases Hydroxy Fatty Acids Accumulation in Transgenic Seeds of Camelina sativa. Front. Plant Sci. 2018, 9. [CrossRef]

44. Dahlqvist, A.; Stahl, U.; Lenman, M.; Banas, A.; Lee, M.; Sandager, L.; Ronne, H.; Stymne, S. Phospholipid:diacylglycerol acyltransferase: An enzyme that catalyzes the acyl-CoA-independent formation of triacylglycerol in yeast and plants. Proc. Natl. Acad. Sci. USA 2000, 97, 6487-6492. [CrossRef] [PubMed]

45. Kim, H.U.; Lee, K.R.; Go, Y.S.; Jung, J.H.; Suh, M.C.; Kim, J.B. Endoplasmic reticulum-located PDAT1-2 from castor bean enhances hydroxy fatty acid accumulation in transgenic plants. Plant Cell Physiol. 2011, 52, 983-993. [CrossRef] [PubMed] 
46. $\quad$ van Erp, H.; Bates, P.D.; Burgal, J.; Shockey, J.; Browse, J. Castor phospholipid:diacylglycerol acyltransferase facilitates efficient metabolism of hydroxy fatty acids in transgenic Arabidopsis. Plant Physiol. 2011, 155, 683-693. [CrossRef]

47. Lee, K.-R.; Chen, G.Q.; Kim, H.U. Current progress towards the metabolic engineering of plant seed oil for hydroxy fatty acids production. Plant Cell Rep. 2015. [CrossRef]

48. Broun, P.; Somerville, C.; Morell, M.K.; Blennow, A.; Kosar-Hashemi, B.; Samuel, M.S. Accumulation of ricinoleic, lesquerolic, and densipolic acids in seeds of transgenic arabidopsis plants that express a fatty acyl hydroxylase cDNA from castor bean. Plant Physiol. 1997, 113, 933-942. [CrossRef]

49. Lu, C.; Fulda, M.; Wallis, J.G.; Browse, J. A high-throughput screen for genes from castor that boost hydroxy fatty acid accumulation in seed oils of transgenic Arabidopsis. Plant J. 2006, 45, 847-856. [CrossRef]

50. Burgal, J.; Shockey, J.; Lu, C.; Dyer, J.; Larson, T.; Graham, I.; Browse, J. Metabolic engineering of hydroxy fatty acid production in plants: RcDGAT2 drives dramatic increases in ricinoleate levels in seed oil. Plant Biotechnol. J. 2008, 6, 819-831. [CrossRef]

51. Shockey, J.; Lager, I.; Stymne, S.; Kotapati, H.K.; Sheffield, J.; Mason, C.; Bates, P.D. Specialized lysophosphatidic acid acyltransferases contribute to unusual fatty acid accumulation in exotic Euphorbiaceae seed oils. Planta 2019, 249, 1285-1299. [CrossRef]

52. Kim, H.U.; Park, M.-E.; Lee, K.-R.; Suh, M.-C.; Chen, G.Q. Variant Castor Lysophosphatidic Acid Acyltransferases Acylate Ricinoleic Acid in Seed Oil. Ind. Crop. Prod. 2020, 150, 112245. [CrossRef]

53. Lunn, D.; Wallis, J.G.; Browse, J. Tri-Hydroxy-Triacylglycerol Is Efficiently Produced by Position-Specific Castor Acyltransferases Plant Physiol. 2019, 179, 1050-1063. [CrossRef]

54. Baulcombe, D. RNA silencing in plants. Nature 2004, 431, 356-363. [CrossRef]

55. Brodersen, P.; Voinnet, O. The diversity of RNA silencing pathways in plants. Trends Genet. 2006, 22, 268-280. [CrossRef]

56. Kang, J.; Snapp, A.R.; Lu, C. Identification of three genes encoding microsomal oleate desaturases (FAD2) from the oilseed crop Camelina sativa. Plant Physiol. Biochem. 2011, 49, 223-229. [CrossRef]

57. Nguyen, H.T.; Silva, J.E.; Podicheti, R.; Macrander, J.; Yang, W.; Nazarenus, T.J.; Nam, J.W.; Jaworski, J.G.; Lu, C.; Scheffler, B.E.; et al. Camelina seed transcriptome: A tool for meal and oil improvement and translational research. Plant Biotechnol. J. 2013, 11, 759-769. [CrossRef]

58. Kumssa, T.T.; Nazarenus, T.J.; Koster, K.L.; Nguyen, H.T.; Cahoon, R.E.; Lu, C.; Cahoon, E.B. Field Performance and Enhanced Oil Oxidative Stability of the Biofuel and Industrial Oilseed Camelina Engineered for Reduced Fatty Acid Polyunsaturation. 2021; in preparation.

59. Hu, Q.A.; Ailhas, J.; Blevins, T.; Klahre, U.; Vazquez, F.; Mette, M.F.; Meins, F. Epigenetic transgenerational effects on RNAi in Arabidopsis. bioRxiv 2020. [CrossRef]

60. McGinnis, K.; Murphy, N.; Carlson, A.R.; Akula, A.; Akula, C.; Basinger, H.; Carlson, M.; Hermanson, P.; Kovacevic, N.; McGill, M.A.; et al. Assessing the Efficiency of RNA Interference for Maize Functional Genomics. Plant Physiol. 2007, 143, 1441-1451. [CrossRef] [PubMed]

61. Chen, G.Q.; Turner, C.; He, X.; Nguyen, T.; McKeon, T.A.; Laudencia-Chingcuanco, D. Expression profiles of genes involved in fatty acid and triacylglycerol synthesis in castor bean (Ricinus communis L.). Lipids 2007, 42, 263-274. [CrossRef] [PubMed]

62. Dauk, M.; Lam, P.; Kunst, L.; Smith, M.A. A FAD2 homologue from Lesquerella lindheimeri has predominantly fatty acid hydroxylase activity. Plant Sci. 2007, 173, 43-49. [CrossRef]

63. Waschburger, E.; Kulcheski, F.R.; Veto, N.M.; Margis, R.; Margis-Pinheiro, M.; Turchetto-Zolet, A.C. Genome-wide analysis of the Glycerol-3-Phosphate Acyltransferase (GPAT) gene family reveals the evolution and diversification of plant GPATs. Genet. Mol. Biol. 2018, 41, 355-370. [CrossRef] [PubMed]

64. Kroon, J.T.M.; Wei, W.; Simon, W.J.; Slabas, A.R. Identification and functional expression of a type 2 acyl-CoA:diacylglycerol acyltransferase (DGAT2) in developing castor bean seeds which has high homology to the major triglyceride biosynthetic enzyme of fungi and animals. Phytochemistry 2006, 67, 2541-2549. [CrossRef]

65. Snapp, A.R.; Kang, J.; Qi, X.; Lu, C. A fatty acid condensing enzyme from Physaria fendleri increases hydroxy fatty acid accumulation in transgenic oilseeds of Camelina sativa. Planta 2014, 240, 599-610. [CrossRef]

66. Lu, C.; Kang, J. Generation of transgenic plants of a potential oilseed crop Camelina sativa by Agrobacterium-mediated transformation. Plant Cell Rep. 2008, 27, 273-278. [CrossRef] [PubMed]

67. Moire, L.; Rezzonico, E.; Goepfert, S.; Poirier, Y. Impact of unusual fatty acid synthesis on futile cycling through beta-oxidation and on gene expression in transgenic plants. Plant Physiol. 2004, 134, 432-442. [CrossRef] [PubMed]

68. Stahl, U.; Carlsson, A.S.; Lenman, M.; Dahlqvist, A.; Huang, B.; Banas, W.; Banas, A.; Stymne, S. Cloning and functional characterization of a phospholipid:diacylglycerol acyltransferase from Arabidopsis. Plant Physiol. 2004, 135, 1324-1335. [CrossRef]

69. Pidkowich, M.S.; Nguyen, H.T.; Heilmann, I.; Ischebeck, T.; Shanklin, J. Modulating seed beta-ketoacyl-acyl carrier protein synthase II level converts the composition of a temperate seed oil to that of a palm-like tropical oil. Proc. Natl. Acad. Sci. USA 2007, 104, 4742-4747. [CrossRef]

70. Wesley, S.V.; Helliwell, C.A.; Smith, N.A.; Wang, M.B.; Rouse, D.T.; Liu, Q.; Gooding, P.S.; Singh, S.P.; Abbott, D.; Stoutjesdijk, P.A.; et al. Construct design for efficient, effective and high-throughput gene silencing in plants. Plant J. 2001, 27, 581-590. [CrossRef]

71. Dierig, D.A.; Tomasi, P.M.; Dahlquist, G.H. Registration of WCL-LY2 high oil Lesquerella fendleri germplasm. Crop Sci. 2001, 41, 604-605. [CrossRef] 
72. Lazo, G.R.; Stein, P.A.; Ludwig, R.A. A DNA transformation-competent Arabidopsis genomic library in Agrobacterium. Nat. Biotechnol. 1991, 9, 963-967. [CrossRef]

73. Butte, W. Rapid method for the determination of fatty acid profiles from fats and oils using trimethylsulphonium hydroxide for transesterification. J. Chromatogr. A 1983, 261, 142-145. [CrossRef]

74. Kim, H.J.; Silva, J.E.; Vu, H.S.; Mockaitis, K.; Nam, J.W.; Cahoon, E.B. Toward production of jet fuel functionality in oilseeds: Identification of FatB acyl-acyl carrier protein thioesterases and evaluation of combinatorial expression strategies in Camelina seeds. J. Exp. Bot. 2015, 66, 4251-4265. [CrossRef] 